\title{
Deuterium retention in self-damaged tungsten
}

B. Tyburska ${ }^{\mathrm{a}, \mathrm{b}},{ }^{*}$, V.Kh. Alimov ${ }^{\mathrm{c}}$, O.V. Ogorodnikova ${ }^{\mathrm{a}}, \mathrm{K}^{\mathrm{a}}$. Schmid ${ }^{\mathrm{a}}$ and K. Ertl ${ }^{\mathrm{a}}$

${ }^{\mathrm{a} I n s t i t u t ~ f u ̈ r ~ P l a s m a p h y s i k, ~ E U R A T O M ~ A s s o c i a t i o n, ~} 85748$ Garching, Germany

${ }^{\mathrm{b}}$ University of Maria Curie-Skłodowska, 20-031 Lublin, Poland

${ }^{\mathrm{c}}$ Tritium Technology Group, Japan Atomic Energy Agency, Tokai, Ibaraki 319-1195, Japan

\begin{abstract}
Surface and sub-surface morphology and deuterium retention in polycrystalline tungsten, undamaged and pre-damaged with $5.5 \mathrm{MeV} \mathrm{W}^{2+}$ ions to damage levels of $0.04,0.4$, and $1.2 \mathrm{dpa}$, with and without subsequent annealing at $1200 \mathrm{~K}$ for $2 \mathrm{~h}$, have been examined after irradiation with low-energy deuterium ions up to a fluence of $1 \times 10^{26} \mathrm{D} / \mathrm{m}^{2}$ at various temperatures. The morphology changes were investigated by scanning electron microscopy in combination with focused ion beam surface cutting. The different hydrogen binding states were investigated by thermal desorption spectroscopy, and the depth profile of the implanted $\mathrm{D}$ was measured by ion beam nuclear reaction analysis.
\end{abstract}

The dependence of the D retention on the damage level and the implanted fluence was studied, and the results show saturation for $0.4 \mathrm{dpa}$ independent of the deuterium implantation fluence. Additionally, it was observed that self-implantation introduces high temperature traps which can almost completely be removed by annealing at $1200 \mathrm{~K}$.

PACS classification codes: $52.40 . \mathrm{Hf}$; 61.72.Qq; 61.80.Jh

* Corresponding author. Address: Institut für Plasmaphysik, EURATOM Association, 85748 Garching, Germany. Tel.: +49 89 32992239; fax: +49 8932992279. 


\section{Introduction}

Due to its favorable physical properties, like low erosion yield and high melting temperature, tungsten (W) is employed as a plasma-facing material in both current and future fusion devices, such as Asdex Upgrade and ITER. As plasma-facing material, W will be subject to intense fluxes of energetic deuterium and tritium particles, as well as $14 \mathrm{MeV}$ neutrons. This implantation process leads to concerns about the influence of neutron damage on tritium retention in W. Deuterium (D) retention and diffusion in damaged W was already investigated by several groups [1], [2], [3], [4], [5] and [6]. Unfortunately, the results are very scattered, and there is no agreement as to in what kind of defects $\mathrm{D}$ is trapped and what the detrapping energy from ion-induced defects is.

In this work, the displacement damage by $5.5 \mathrm{MeV} \mathrm{W}^{2+}$ ions was used to simulate the damage morphology typical for neutron irradiation, i.e., dense cascades with large vacancy clusters were generated [7]. Additionally, the irradiation with W ions, as opposed to some other heavy elements, prevented the formation of chemical compounds which may have served as additional trapping sites for hydrogen. According to the ITER Nuclear Analysis Report [8], W divertor tiles will suffer neutron-induced damage of up to 0.7 displacements per atom (dpa). In this work, W was irradiated with $\mathrm{W}$ ions to damage levels of $0.04,0.4$, and $1.2 \mathrm{dpa}$ and then irradiated with deuterium to determine the amount of $\mathrm{D}$ trap sites produced per dpa. The purpose of our research was to study the $\mathrm{D}$ retention in relation to the damage level, deuterium fluence, and irradiation temperature.

\section{Experimental}

The samples were prepared from polycrystalline W (99.95 wt.\% purity) delivered by Goodfellow Cambridge Limited. A $500 \mu \mathrm{m}$ thick W plate was mechanically polished to mirror-like finish and cut into $10 \times 10 \mathrm{~mm}^{2}$ and $12 \times 15 \mathrm{~mm}^{2}$ size samples. The samples were then outgased at $1200 \mathrm{~K}$ for $2 \mathrm{~h}$ in vacuum with a background pressure of $2 \times 10^{-6} \mathrm{~Pa}$.

The $\mathrm{W}$ samples were irradiated initially with $\mathrm{W}$ ions and then with $\mathrm{D}$ ions. The samples' treatment is shown in Table 1 . Irradiation with $5.5 \mathrm{MeV} \mathrm{W}^{2+}$ ions (so-called selfimplantation) was performed in an implantation chamber connected to the $3 \mathrm{MV}$ tandem accelerators. The background pressure in this chamber was better than $1 \times 10^{-5} \mathrm{~Pa}$. In 
order to obtain a homogeneous fluence distribution over the sample surface, a beam of W ions was swept vertically and horizontally over the target. Beam position, ion flux, and fluence were controlled by an arrangement of four small-diameter Faraday cups located at the four corners of the sample mask. To check whether the sample/Faraday cup arrangement was working properly, Au ions were implanted into Si substrate to a fluence of $1.8 \times 10^{20} \mathrm{Au}^{+} / \mathrm{m}^{2}$, and the thusly prepared sample was analyzed by Rutherford backscattering (RBS). The difference between the current measurementbased value and the value obtained from RBS was within the experimental uncertainties of the RBS measurement. The temperature of the sample was measured by a thermocouple attached directly to the target and was kept around $290 \mathrm{~K}$ during the $\mathrm{W}$ ion bombardment.

The implantation with $5.5 \mathrm{MeV} \mathrm{W}^{2+}$ ions with a projected range $R_{\mathrm{p}}=400 \mathrm{~nm}$ was done at a flux of $3 \times 10^{15} \mathrm{~W}^{2+} /\left(\mathrm{m}^{2} \mathrm{~s}\right)$ to fluences of $3.5 \times 10^{16}, 3.5 \times 10^{17}$, and $1 \times 10^{18} \mathrm{~W}^{2+} / \mathrm{m}^{2}$, which correspond to damage levels of $0.04,0.4$, and $1.2 \mathrm{dpa}$, respectively. These dpa levels are reached in the maximum of the damage profile and were calculated according to Eq. (1):

$$
d p a_{\text {peak }}=\frac{N_{\text {displacement }} \Phi}{N_{\mathrm{W}}}
$$

The number of displacements $\left(N_{\text {displacement }}\left[\frac{10^{7}}{i \text { ion } \cdot \mathrm{m}}\right]\right)$ was taken from a TRIM calculation (SRIM 2008.03, "full cascade option" [9]). Since $E_{\mathrm{d}}$ depends on the crystal orientation, the minimum value of $68 \mathrm{eV}[10]$ was taken for the damage simulations. $\Phi\left[\frac{\mathrm{ion}}{\mathrm{m}^{2}}\right\rfloor$ denotes the implantation fluence, and $N_{\mathrm{w}}\left\lfloor\frac{\mathrm{at}}{\mathrm{m}^{3}}\right\rfloor$ the $\mathrm{W}$ atomic density. Subsequent to displacement, the defects produced in the collision cascade diffuse and annihilate. These effects are not included in the program and the damage structure will be far more complex than the calculated one. The SRIM calculation shows that the maximum damage concentration is located at depths of $0.2-0.4 \mu \mathrm{m}$ (Fig. 1). After the $\mathrm{W}$ pre-implantation, half of the samples were annealed at $1200 \mathrm{~K}$ for $2 \mathrm{~h}$ in vacuum at a background pressure of $2 \times 10^{-6} \mathrm{~Pa}$. The damaged $\mathrm{W}$ samples were divided into two batches: the batch labeled "A" contains damaged W samples without post-implantation annealing, whereas the 
self-implanted samples annealed at $1200 \mathrm{~K}$ for $2 \mathrm{~h}$ comprise to the batch " $\mathrm{B}$ ". Additionally, undamaged $\mathrm{W}$ targets were used for comparison.

The undamaged ( $0 \mathrm{dpa})$ and damaged $\mathrm{W}$ samples were subjected to $\mathrm{D}$ ion irradiation and D plasma exposure. The irradiation with D ions was performed at IPP Garching in a vacuum chamber connected to a high current ion source. A $3600 \mathrm{~V} \mathrm{D}_{3}^{+}$ion beam was extracted from the ion source, magnetically filtered, and decelerated in front of the sample by a positive target bias of $3000 \mathrm{~V}$ to achieve $600 \mathrm{eV} \mathrm{D}_{3}^{+}$corresponding to $200 \mathrm{eV} / \mathrm{D}$. The $\mathrm{W}$ samples were irradiated at an ion flux of $4 \times 10^{19} \mathrm{D} /\left(\mathrm{m}^{2} \mathrm{~s}\right)$ to fluences of $5 \times 10^{23}$ and $3 \times 10^{24} \mathrm{D} / \mathrm{m}^{2}$. During irradiation, the $\mathrm{W}$ samples were heated up to $320 \mathrm{~K}$ by the ion beam. By electron bombardment from the rear, the irradiation temperature could also be fixed at $470 \mathrm{~K}$.

Some of the W samples were not implanted at IPP Garching but were exposed to a plasma beam generated in the linear plasma generator [11] installed at JAEA, Tokai. The dominant ion species in the plasma beam was $\mathrm{D}_{2}^{+}$with an ion flux fraction of over $80 \%$. The samples were biased at $-80 \mathrm{~V}$ resulting in the incident energy of $38 \mathrm{eV} / \mathrm{D}$, taking into account the plasma potential of about $-4 \mathrm{~V}$ measured by a Langmuir probe. The incident deuterium ion flux was $\approx 10^{22} \mathrm{D} /\left(\mathrm{m}^{2} \mathrm{~s}\right)$. The samples were exposed to an ion fluence of $1 \times 10^{26} \mathrm{D} / \mathrm{m}^{2}$. All samples were heated by the plasma itself, and the exposure temperature was determined by the thermal contact between the sample and the cooled holder. The resulting sample temperatures during implantation were 350 and $470 \mathrm{~K}$.

It should be noted that in both implantation setups the $\mathrm{D}$ ion implantation range (several nanometers) was much smaller than the depth of the radiation defects generated by the $\mathrm{W}$ ions (several hundred nanometers).

The $\mathrm{D}$ concentration in the near-surface layer (at depths up to about $0.5 \mu \mathrm{m}$ ) was measured by means of the $\mathrm{D}\left({ }^{3} \mathrm{He}, \alpha\right) \mathrm{p}$ reaction at a ${ }^{3} \mathrm{He}$ energy of $0.69 \mathrm{MeV}$. For this near-surface region, the $\alpha$ particles from the nuclear reaction were energy-analyzed with a small-angle $(9.16 \mathrm{msr})$ surface barrier detector at a laboratory scattering angle of $102^{\circ}$. The $\alpha$ spectrum was transformed into a D depth profile using the SIMNRA program [12]. To determine the $\mathrm{D}$ concentration at larger depths, an analyzing beam of ${ }^{3} \mathrm{He}$ ions with energies varying from 0.69 to $4.0 \mathrm{MeV}$ was used [13] and [14]. The protons from 
the $\mathrm{D}\left({ }^{3} \mathrm{He}, \mathrm{p}\right) \alpha$ nuclear reaction were counted using a wide-angle $(29.94 \mathrm{msr})$ proton detector placed at a scattering angle of $135^{\circ}$. A Ni foil with a thickness of $5 \mu \mathrm{m}$ and a $12 \mu \mathrm{m}$ Mylar foil were positioned in front of the detector to absorb elastically scattered

${ }^{3} \mathrm{He}$ ions and $\alpha$ particles from the $\mathrm{D}\left({ }^{3} \mathrm{He}, \mathrm{p}\right) \alpha$ nuclear reaction. In order to extend the analysis of the $\mathrm{D}$ concentration to depths of several micrometers, the program NRAUtil was used for the deconvolution of the proton yields measured at different ${ }^{3} \mathrm{He}$ ion energies. NRAUtil remotely controls SIMNRA via its ole interface and uses it to calculate the proton peak counts resulting from a given $\mathrm{D}$ depth profile for the different ${ }^{3} \mathrm{He}$ ion energies. By iteratively adjusting the input $\mathrm{D}$ depth profile, the calculated proton peak integrals can be matched with the experimentally determined ones [13] and [14]. The initial input D depth distribution was based on the near-surface depth profile obtained from the $\alpha$ particles.

TDS measurements were performed in a second vacuum chamber connected to the high current ion source at IPP Garching. The temperature of the sample was measured by a K-type thermocouple attached to the target. By means of electrons bombardment the sample was heated up to $1100 \mathrm{~K}$ with a ramping rate of $1.2 \mathrm{~K} / \mathrm{s}$. During heating, the HD (mass 3 ) and $\mathrm{D}_{2}$ (mass 4) molecules were recorded by a quadruple mass spectrometer (Pfeiffer QMG700). The QMS signals were not absolutely calibrated.

The surface topography and three-dimensional sub-surface morphology of the W samples were examined using a field emission scanning electron microscope combined with a focused ion beam (HELIOS NanoLab 600 DualBeam, FEI). A Ga ion beam allowed surface cross-sectioning after selecting a certain micrometer-sized feature on the sample, investigating its surface topography and analyzing its morphology beneath the surface.

\section{Results and discussion}

Fig. 2 shows the damage level dependence of $\mathrm{D}$ retention up to $7 \mu \mathrm{m}$ in undamaged, pre-implanted, as well as pre-implanted and post-annealed W irradiated at 320-350 and $470 \mathrm{~K}$. In samples from batch "A", we observed a nonlinear increment of D retention with dpa which reaches saturation at around 0.4 dpa. Furthermore, no influence of the D implantation fluence on the onset of the saturation is visible. This means that linear increase of dpa do not lead to linear increase of trap density. Retention in all samples with post-annealed defects is similar for the low temperature implantations and 
comparable to the retention from undamaged targets (Fig. 2). In the case of the samples from batch "B" which were irradiated at $470 \mathrm{~K}$ ( $\underline{\text { Fig. } 2})$, the D retention dependence on implantation fluence is clearly pronounced. D diffusion at $470 \mathrm{~K}$ is higher and can therefore reach traps which are located deeper in the sample. For all samples, D concentration at up to $7 \mu \mathrm{m}$ is higher for $320-350 \mathrm{~K}$ irradiation than for $470 \mathrm{~K}$. When looking at un-calibrated TDS data (not shown) this tendency is reversed, suggesting higher bulk D retention for samples implanted at $470 \mathrm{~K}$, an effect which is not unexpected due to the higher diffusion of $\mathrm{D}$ at $470 \mathrm{~K}$.

Deuterium depth profiles in the undamaged $\mathrm{W}$ samples exposed to the D plasma at $470 \mathrm{~K}$ are characterized by a sharp near-surface concentration and a decrease of the concentration with depth (Fig. 3). For the damaged W samples, the D concentration at depths up to $1.5 \mu \mathrm{m}$ is higher than for undamaged ones and reaches a plateau at around $0.01 \mathrm{D} / \mathrm{W}$ for all fluences. In the $1.5-7 \mu \mathrm{m}$ region, the $\mathrm{D}$ concentration is at a level of $\sim$ 0.0001 at. $\%$ and is similar for all samples. Apparently, the radiation-induced defects serve as trap sites for deuterium atoms diffusing from the near-surface layer. The D concentration in each damaged and annealed sample is significantly lower than in the un-annealed samples damaged up to the same dpa level but higher than in undamaged $\mathrm{W}$ (Fig. 3). This is also representative for implantations at $200 \mathrm{eV}$ in high current source samples.

Deuterium thermal desorption spectra for undamaged and damaged $\mathrm{W}$ samples irradiated with D ions to a fluence of $3 \times 10^{24} \mathrm{D} / \mathrm{m}^{2}$ at 320 and $470 \mathrm{~K}$ clearly show that high temperature trap sites are present in the un-annealed damaged W. A TDS peak around $800 \mathrm{~K}$ is observed only for the damaged, un-annealed samples (Fig. 4). Its height depends on the damage level. For samples damaged at 0.04 dpa, only a broad shoulder is observed at this temperature, suggesting that $\mathrm{W}$ self-implantation at this damage level did not introduce many defects.

The peak at around $800 \mathrm{~K}$ had already been seen by Fukumoto et al. [4] and [5], Arkhipov et al. [3], Oliver et al. [2]. Fukumoto attributed it to D desorption from vacancy clusters. Oliver, in contrast, claims that $\mathrm{D}$ release at this temperature cannot be ascribed to ion-induced defects but to natural traps present in $\mathrm{W}$. We agree with Fukamoto. Oliver et al. [2] observed in his work full trap removal after annealing at $1200 \mathrm{~K}$ for $6 \mathrm{~h}$. This is quite similar to our result. Because of this, we believe that the traps introduced by self-implantation are vacancy clusters and not voids as suggested by 
van Veen et al. [1]. The temperature of $1200 \mathrm{~K}$ is too low to anneal out voids [15]. Our assumption of deuterium being trapped by vacancy clusters is supported by field ion microscopy studies (FIM) where no voids but interstitials, vacancies, and vacancy clusters were observed in W irradiated by neutrons [19], [20] and [21]. Additionally, FIM and isochronal resistivity measurements [22] and [23] report the recovery of ninduced defects mainly at $\backsim 0.15 T_{\mathrm{m}}$ and $\backsim 0.31 T_{\mathrm{m}}$, where $T_{\mathrm{m}}$ is the $\mathrm{W}$ melting temperature. $0.15 T_{\mathrm{m}}$ is called Stage III and is attributed to interstitial annihilation at immobile vacancies. Stage IV at $0.31 T_{\mathrm{m}}$ is attributed to vacancy and vacancy clusters recovery. According to these studies, the full defect removal takes place at around $1350 \mathrm{~K}$. The deuterium detrapping temperature from vacancy clusters at $800 \mathrm{~K}$ and almost full ion-induced defects removal at $1200 \mathrm{~K}$ are in a good agreement with afore mentioned studies.

The TDS spectra from all samples implanted with D at 320-350 K have two peaks: a low-temperature peak with a maximum at about $420-450 \mathrm{~K}$ and a middle-temperature peak with a maximum at about $640-670 \mathrm{~K}$. These peaks were already observed, e.g., by Ogorodnikova et al. [16] in undamaged W. For undamaged samples, these peaks are slightly higher and better separated than for damaged targets after annealing. This means that pre-implantation not only produces high energy traps but also introduces lower energy ones. Heating at $1200 \mathrm{~K}$ for $2 \mathrm{~h}$ decreases the number of these traps but not to their initial level.

The exposure of W samples from batches " $A$ " and "B" to low-energy ( $38 \mathrm{eV} / \mathrm{D})$, high flux $\left(10^{22} \mathrm{D} /\left(\mathrm{m}^{2} \mathrm{~s}\right)\right) \mathrm{D}$ plasma at $470 \mathrm{~K}$ to a fluence of $1 \times 10^{26} \mathrm{D} / \mathrm{m}^{2}$ led to the appearance of sparse blisters with sizes of 5-17 $\mu \mathrm{m}$ on the exposed surface and formation of cracks along the grain boundaries far beyond the implantation zone (ig 5). In the case of undamaged $\mathrm{W}$ exposed to the $\mathrm{D}$ plasma, the cracks are formed just below the surface (not shown), and the surface morphology is characterized by small dense blisters $(<1 \mu \mathrm{m}$ in size $)$. It is therefore concluded that the deeper the crack formation takes place, the larger is the blister diameter. Crack production was not observed for lower fluences irradiations. Only surface of undamaged W sample exposed to a fluence of $3 \times 10^{24} \mathrm{D} / \mathrm{m}^{2}$ displayed some blisters with diameters $<1 \mu \mathrm{m}$ (not shown). The crack and blister observations are summarized in Table 2. 
The absence of cracks in the damage zone in batches " $\mathrm{A}$ " and " $\mathrm{B}$ " is an additional confirmation of high trap site density. In the presence of radiation-induced defects, the effective solubility of D is increased and therefore the stress due the implanted D decreases and is not high enough for crack production as would be the case for undamaged W. Once the stress level in the D implanted W leads to mechanical failure at local weak spots like grain boundaries the D from the surrounding $\mathrm{W}$ bulk effuses into the crack until the $\mathrm{D}_{2}$ pressure inside the crack equilibrates the chemical potentials of $\mathrm{D}$ in the bulk [17], [18] and [26]. Due to the low solubility of D in W these pressure can be strong enough to further widen the crack or push grains out of the surface.

Also the extension of the damage zone might hold back blister formation or shift their creation to a higher D flux.

\section{Summary}

$\mathrm{D}$ retention in polycrystalline $\mathrm{W}$ was studied as function of damage level, fluence, and temperature of D irradiation. Self-implantation of $\mathrm{W}$ by heavy ions results in $\mathrm{D}$ retention in high temperature trapping sites. These traps, comprised mostly of vacancies and vacancy clusters, can be almost fully removed by annealing at $1200 \mathrm{~K}$ for $2 \mathrm{~h}$. However, all neutron-produced traps in $\mathrm{W}$ should be recovered above $1350 \mathrm{~K}$ (after the Stage IV annealing) [22].

Radiation-induced trap sites become more numerous with increasing dpa, and their number reaches saturation at a level of 0.4 dpa. D concentration in the sub-surface region is fluence indifferent, and the trap concentration reaches a plateau at $1 \%$ for samples irradiated at $320-350 \mathrm{~K}$ and a little bit lower for $470 \mathrm{~K}$ irradiation. W monoblocks are to be used in water-cooled lithium lead (WCLL) reactors [24] and [25]. The average temperature of such monoblocks will be around $600 \mathrm{~K}$ which is still lower than the D detrapping temperature from radiation-induced defects. Therefore, these monoblocks may be efficient sinks for tritium. No concerns about tritium retention arise in other reactor concepts as they will be operated at higher temperatures.

The combination of high flux D irradiation and excess vacancies appears to inhibit crack formation in the near-surface region and shifts the formation of cracks far beyond the implantation zone. The formation of these deep cracks may result in blister 
formation on the W surface. Since neutron-induced defects in W will be present in the entire material this may suppress cracks and blisters formation.

\section{Acknowledgment}

We would like to thank J. Dorner, M. Fußeder, and A. Weghorn for technical assistance, as well as S. Linding and M. Rasinski for their help in creating the SEM/FIB pictures. 


\section{References}

[1] A. van Veen, H.A. Filius, J. de Vries, K.R. Bijkerk, G.J. Rozing and D. Segers, J. Nucl. Mater. 155-157 (1988), pp. 1113-1117.

[2] B.M. Oliver, R.A. Causey and S.A. Maloy, J. Nucl. Mater. 329-333 (2004), pp. 977-981.

[3] I.I. Arkhipov, S.L. Kanashenko, V.M. Sharapov, R.Kh. Zalavutdinov and A.E. Gorodetsky, J. Nucl. Mater. 363-365 (2007), pp. 1168-1172.

[4] M. Fukumoto, H. Kashiwagi, Y. Ohtsuka, Y. Ueda, M. Taniguchi, T. Inoue, K. Sakamoto, J. Yagyu, T. Arai, I. Takagi and T. Kawamura, J. Nucl. Mater. 390-391 (2009), pp. 572-575.

[5] M. Fukumoto, H. Kashiwagi, Y. Ohtsuka, Y. Ueda, Y. Nobuta, J. Yagyu, T. Arai, M. Taniguchi, T. Inoue and K. Sakamoto, J. Nucl. Mater. 386-388 (2009), pp. 768-771.

[6] W.R. Wampler and R.P. Doerner, Nucl. Fusion 49 (2009), p. 115023.

[7] G.S. Was, Fundamentals of Radiation Material Science, Metals and Alloys, Springer (2007).

[8] H. Iida, V. Khripunov, L. Petrizzi, G. Federici, ITER Nuclear Analysis Report, G 73 DDD 2 W 0.2 (2004).

[9] http://srim.org.

[10] Q. Xu, T. Yoshiie and H.C. Huang, Nucl. Instrum. Methods Phys. Res. Sect. B206 (2003), pp. 123-126.

[11] G.-N. Luo, W.M. Shu, H. Nakamura, S. O’hira and M. Nishi, Rev. Sci. Instrum. 75 (2004), pp. 4374-4378.

[12] M. Mayer, SIMNRA USer's Guide, Tech. Report IPP 9/113, Max-Planck-Institut fuer Plasmaphysik, Garching, Germany, 1997.

[13] V. Kh. Alimov, M. Mayer and J. Roth, Nucl. Instrum. Methods Phys. Res. Sect. B234 (2005), pp. 169-175.

[14] M. Mayer, E. Gauthier, K. Sugiyama and U. von Toussaint, Nucl. Instrum. Methods Phys. Res. Sect. B267 (2009), pp. 506-512.

[15] H. Eleveld and A. van Veen, J. Nucl. Mater. 191-194 (1992), pp. 433-438.

[16] O.V. Ogorodnikova, J. Roth and M. Mayer, J. Nucl. Mater. 373 (2008), pp. 254258.

[17] M. Fukumoto, Y. Ohtsuka, Y. Ueda, M. Taniguchi, M. Kashiwagi, T. Inoue and K. Sakamoto, J. Nucl. Mater. 375 (2008), pp. 224-228.

[18] V.Kh. Alimov and J. Roth, Phys. Scr. T128 (2007), pp. 6-13. 
[19] M. Attardo and J.M. Galligan, Phys. Stat. Sol. 16 (1966), pp. 449-457.

[20] M. Attardo, J.M. Galligan and J.G.Y. Chow, Phys. Rev. Lett. 19 (1967), pp. 73-74.

[21] D. Jeannotte and J.M. Galligan, Phys. Rev. Lett. 19 (1967), pp. 232-233.

[22] L.K. Keys, J.P. Smith and J. Moteff, Phys. Rev. 176 (1968), pp. 851-856.

[23] L.K. Keys and J. Moteff, J. Nucl. Mater. 34 (1970), pp. 260-280.

[24] P. Norajitra, S.I. Abdel-Khalik, L.M. Giancarli, T. Ihli, G. Janeschitz, S. Malang, I.V. Mazul and P. Sardain, Fus. Eng. Des. 83 (2008), pp. 893-902.

[25] P. Sardain, B. Michel, L. Giancarli, A. Li Puma, Y. Poitevin, J. Szczepanski, D.

Maisonnier, D. Ward, U. Fischer, P. Pereslavtsev, A. Natalizio, J. Collen and A. Orden Martinez, Fus. Eng. Des. 69 (2003), pp. 769-774.

[26] R. Kirchheim, Phys. Scr. T94 (2001), pp. 58-67. 
Figures and tables

$500 \mu \mathrm{m}$ PCW, mirror-like polished, outgased $1200 \mathrm{~K}, 2 \mathrm{~h}$

STEP 1:

$5.5 \mathrm{MeV}$ tungsten

self-implantation, $\mathrm{RT}$

$\begin{array}{crrr}\text { 0 dpa } & \mathbf{0 . 0 4} \text { dpa } & \text { 0.4 dpa } & \text { 1.2 dpa } \\ \text { Undamaged } & 3.5 \times 10^{16} \mathrm{~W}^{2+} / & 3.5 \times 10^{17} \mathrm{~W}^{2+} / & 1 \times 10^{18} \mathrm{~W}^{2+} / \mathrm{m} \\ \mathrm{m}^{2} & \mathrm{~m}^{2} & 2^{2}\end{array}$

STEP 2:

No annealing (batch " $A$ ")

\section{Heat treatment}

or

1200 K, 2 h (batch “B”)

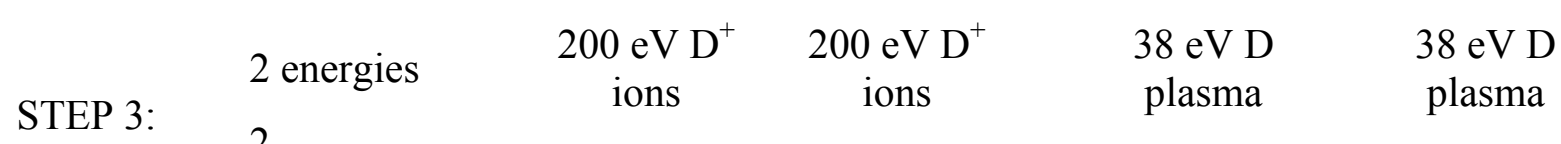

$\begin{array}{llllll}\text { Deuterium temperature } & 320 \mathrm{~K} & 470 \mathrm{~K} & 350 \mathrm{~K} & \mathbf{4 7 0} \mathrm{K}\end{array}$

implantati $\mathrm{S}$

on

3 fluences

$\begin{aligned} & 5 \times 10^{23} \mathrm{D}^{+} / \mathrm{m}^{2} \\ & 3 \times 10^{24} \mathrm{D}^{+} / \mathrm{m}^{2}\end{aligned} \quad 1 \times 10^{26} \mathrm{D} / \mathrm{m}^{2}$

Table 1 Sequence of sample preparation 


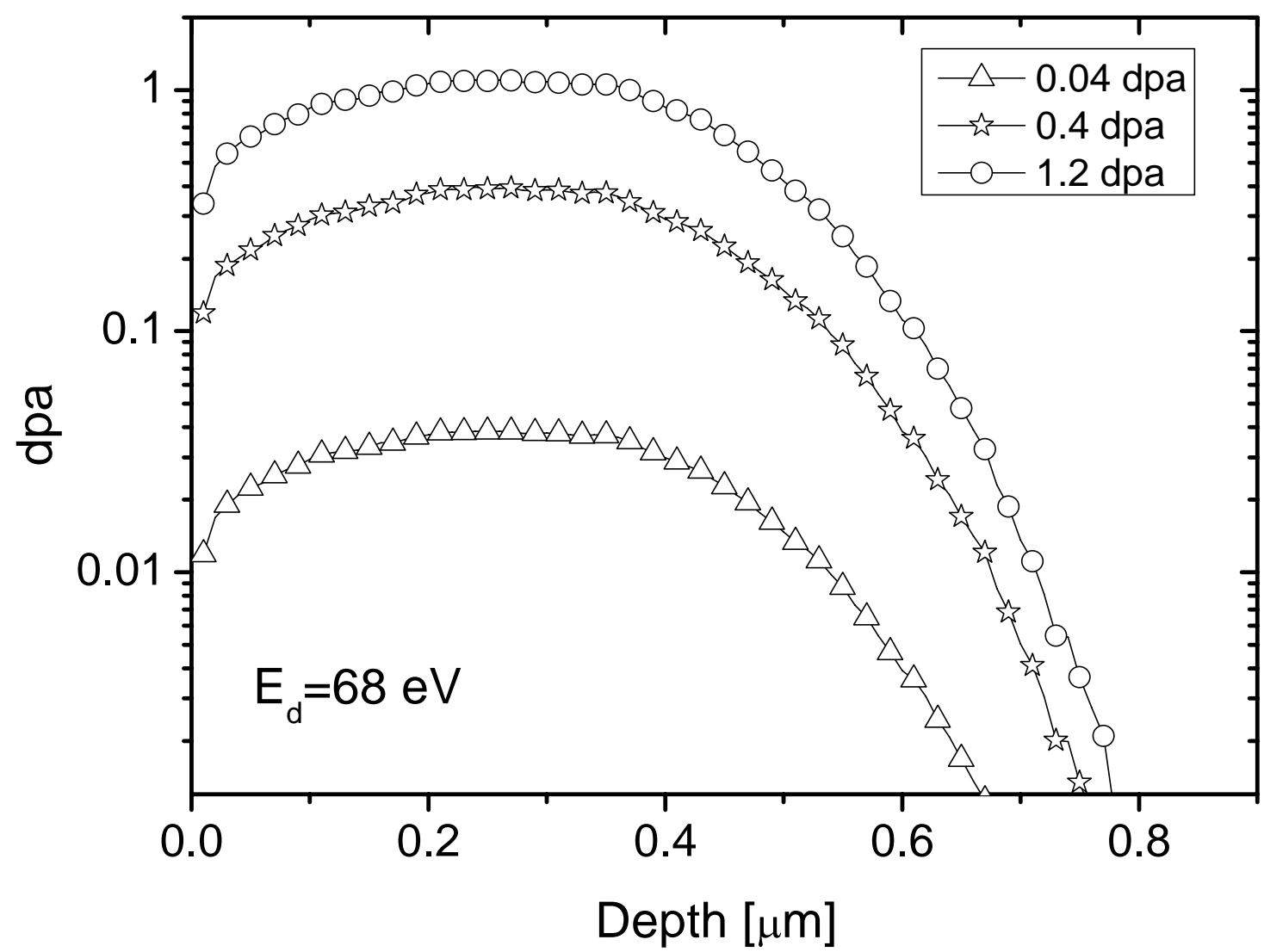

Figure 1 Damage distributions in $\mathrm{W}$ irradiated with $5.5 \mathrm{MeV} \mathrm{W}^{2+}$ ions to damage levels of 0.04, 0.4, and $1.2 \mathrm{dpa}$ 


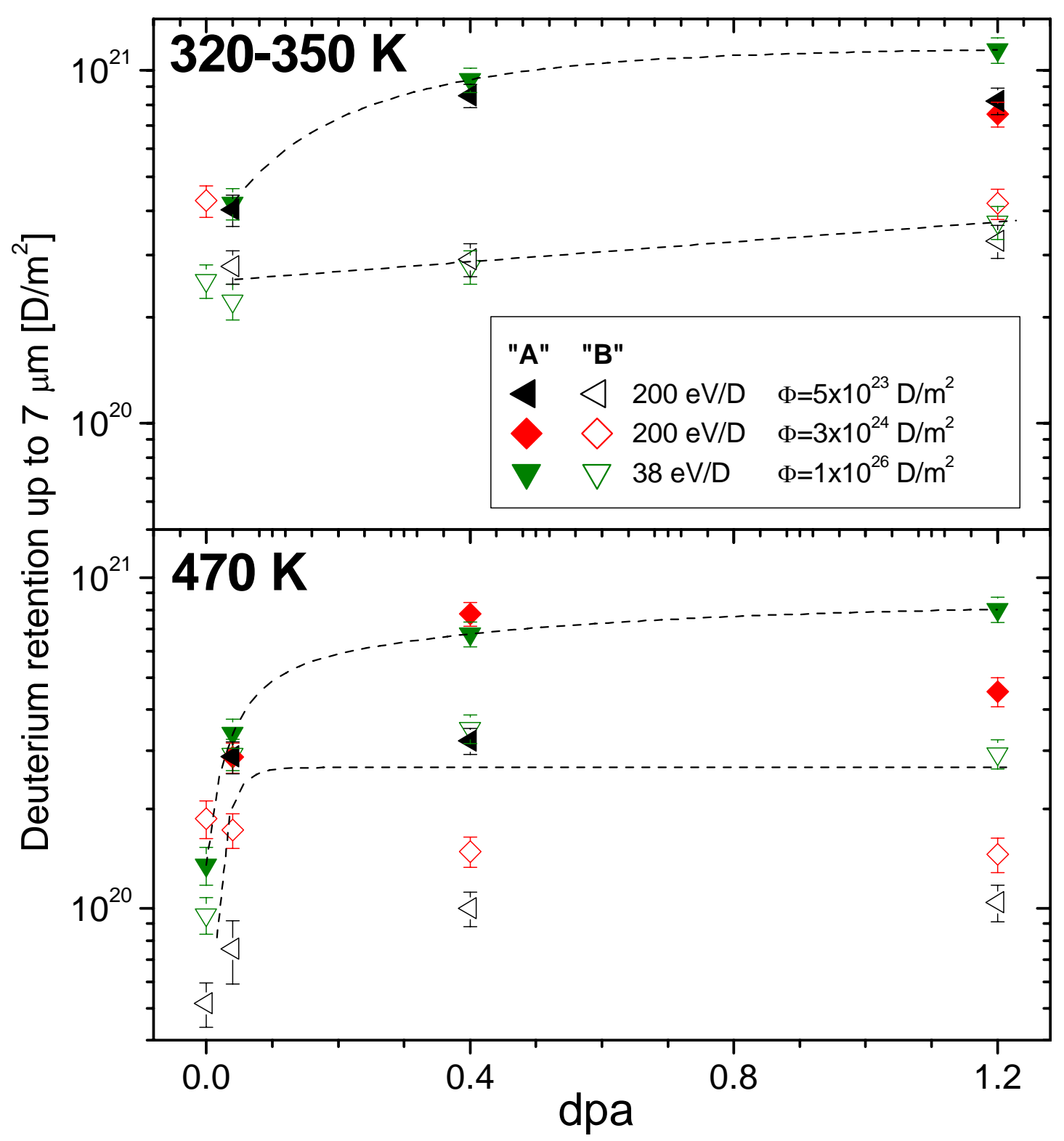

Figure 2 Deuterium retention vs. number of displacements for $W$, undamaged and pre-damaged with $5.5 \mathrm{MeV} \mathrm{W}^{2+}$ ions to damage levels of $0.04,0.4$, and 1.2 dpa with and without subsequent annealing at $1200 \mathrm{~K}$ for $2 \mathrm{~h}$, after irradiation with 38 and $200 \mathrm{eV} \mathrm{D}$ ions at 320-350 K (upper) and $470 \mathrm{~K}$ (lower) to ion fluences of $5 \times 10^{23}$, $3 \times 10^{24}$, and $1 \times 10^{26} \mathrm{D} / \mathrm{m}^{2}$. Data for the samples without ("A") and with the annealing ("B”) are indicated with solid and open symbols, respectively. Dashed lines are to guide the eyes. 

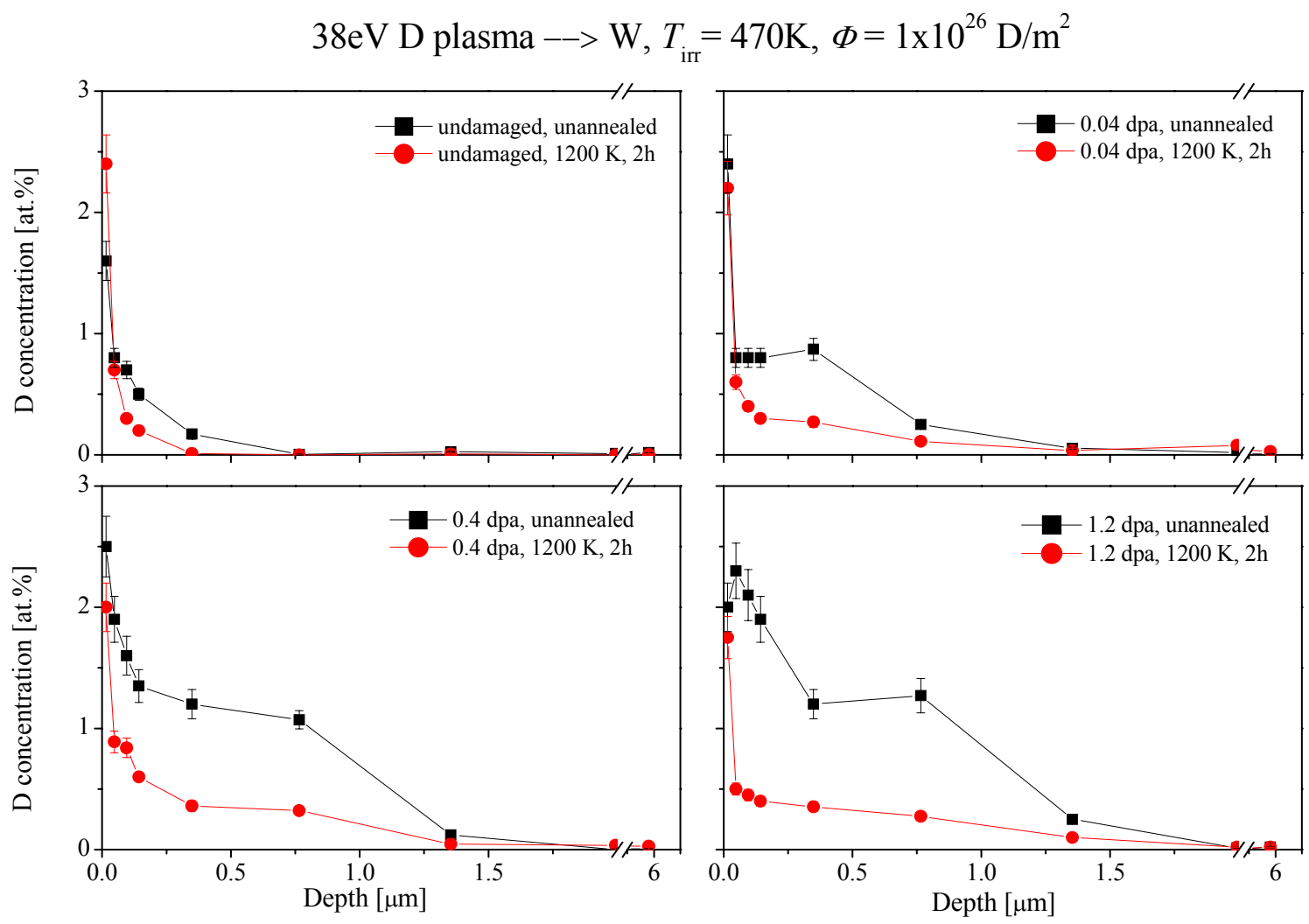

Figure 3 Depth profiles of deuterium trapped in polycrystalline W, undamaged and pre-damaged with $5.5 \mathrm{MeV} \mathrm{W}^{2+}$ ions to damage levels of $0.04,0.4$, and 1.2 dpa with and without subsequent annealing at $1200 \mathrm{~K}$ for $2 \mathrm{~h}$, after irradiation with $38 \mathrm{eV} \mathrm{D}$ ions to a fluence of $1 \times 10^{26} \mathrm{D} / \mathrm{m}^{2}$ at $470 \mathrm{~K}$. 


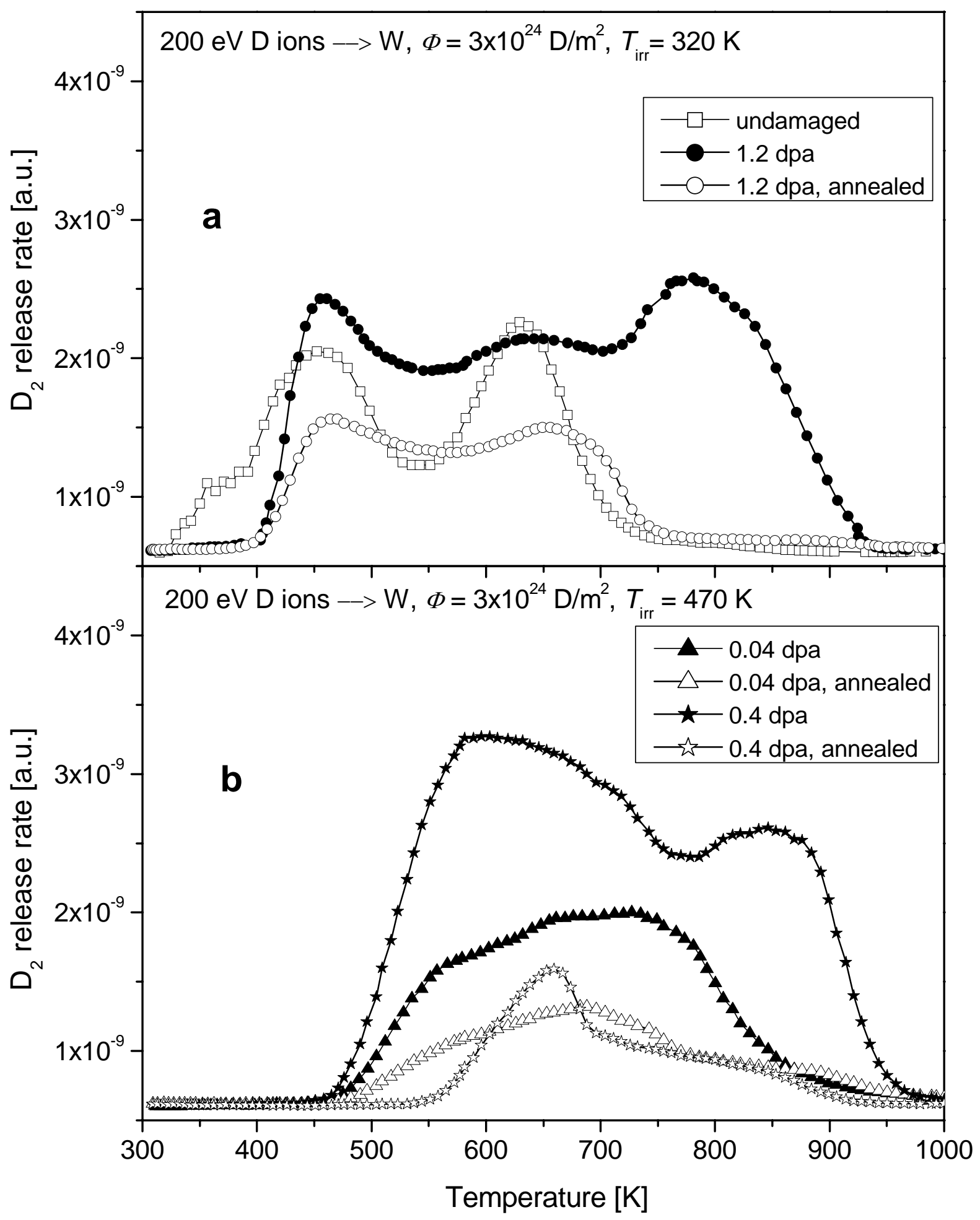

Figure 4 Experimental thermal desorption spectra of PCW samples irradiated with $200 \mathrm{eV} \mathrm{D}^{+}$ions at (a) $320 \mathrm{~K}$ and (b) $470 \mathrm{~K}$, with a fluence of $3 \times 10^{24} \mathrm{D} / \mathrm{m}^{2}$. The heating rate was $1.2 \mathrm{~K} / \mathrm{s}$. 


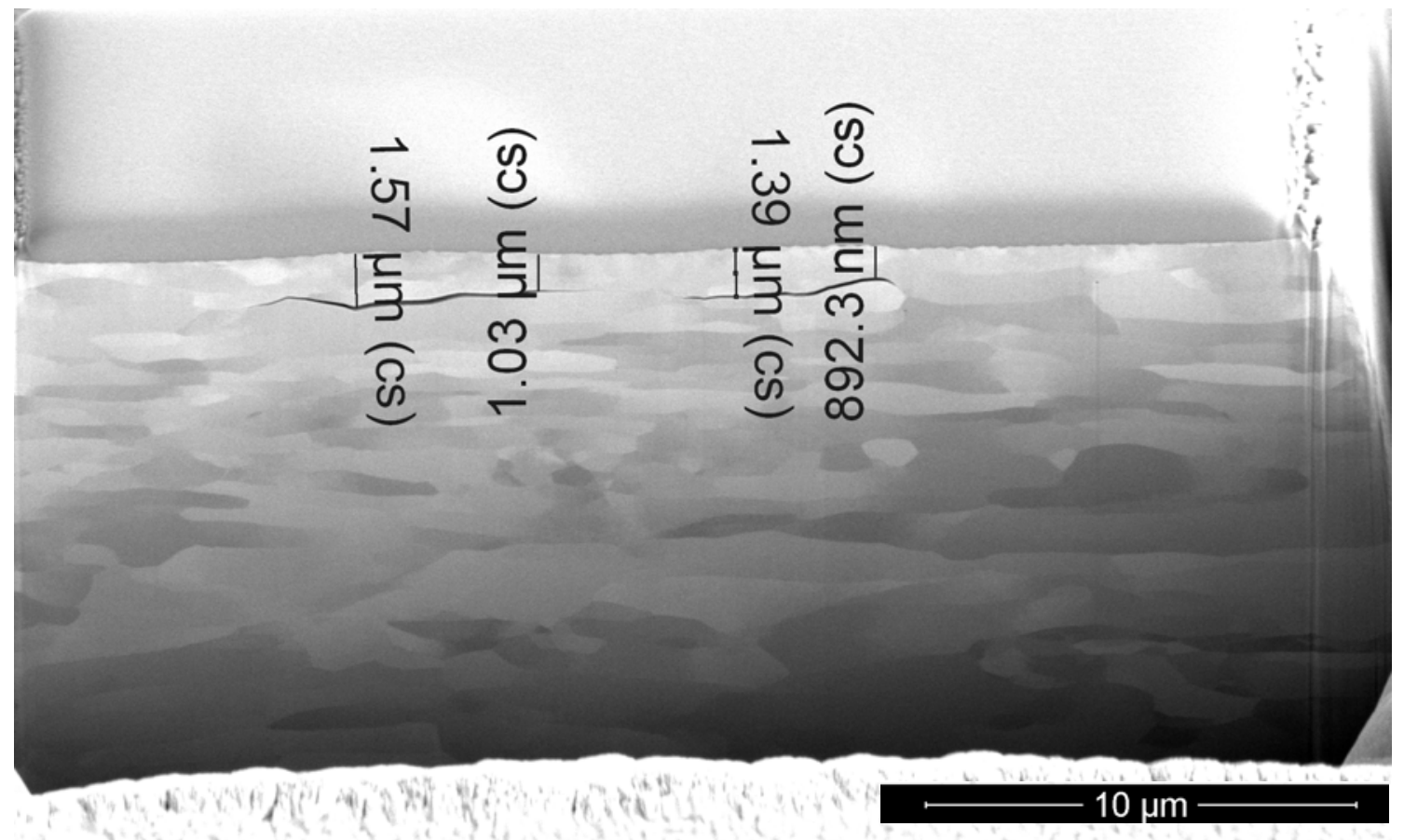

Figure 5 Cross-section of polycrystalline $\mathrm{W}$ pre-damaged with $5.5 \mathrm{MeV} \mathrm{W}^{2+}$ ions to 1.2 dpa and then exposed to a low-energy (38 eV/D) $\mathrm{D}$ plasma at $470 \mathrm{~K}$ to an ion fluence of $1 \times 10^{26} \mathrm{D} / \mathrm{m}^{2}$. Note that prior to the cross-sectioning the surfaces were coated with a Pt-C film. 
Low flux D irradiation

$$
4 \times 10^{19} \frac{\mathrm{D}}{\mathrm{m}^{2} \mathrm{~s}}
$$

No cracks

Undamaged W

Batch "A" and "B"
Blisters $<1 \mu \mathrm{m}$

No cracks

No blisters
High flux D irradiation

$$
1 \times 10^{22} \frac{\mathrm{D}}{\mathrm{m}^{2} \mathrm{~s}}
$$

Cracks at depth $<0.1 \mu \mathrm{m}$

Blisters $<1 \mu \mathrm{m}$

Cracks at depth 1-2 $\mu \mathrm{m}$

Blisters 5-17 $\mu \mathrm{m}$

Table 2 Crack and blister sizes observed by SEM and FIB for undamaged and damaged tungsten irradiated at low and high deuterium flux. The observations are irradiation temperature independent. 